\title{
Fatigue Measurements in Systemic Lupus Erythematosus
}

\author{
Ariane Barbacki, Michelle Petri, Antonio Aviña-Zubieta, Graciela S. Alarcón, and Sasha Bernatsky
}

ABSTRACT. Objective. Fatigue is a frequent, disabling issue in systemic lupus erythematosus (SLE). It is, however, difficult to quantify. The Ad Hoc Committee on SLE Response Criteria for Fatigue in 2007 recommended using the Krupp Fatigue Severity Scale (FSS). Since then, the Functional Assessment of Chronic Illness Therapy (FACIT)-Fatigue Scale has also been validated in SLE. We performed a review of instruments used to measure fatigue in adult SLE patients from 2007 onward.

Methods. We searched PubMed, Medline, and Embase (January 2008-October 2017), identifying clinical trials and observational studies in adult SLE, where fatigue was a specifically measured outcome. All English and French studies were reviewed to determine fatigue measures and results.

Results. Thirty-seven studies met inclusion criteria. Eight scales were used. The visual analog scale (VAS), FSS, and FACIT-Fatigue Scale were most frequent. FSS was the most often used instrument in both clinical trials and observational studies. Twenty-five of the 37 studies demonstrated a difference in fatigue that was statistically significant and clinically meaningful. Of the 12 studies that did not, 6 used FSS, 3 used VAS, 2 used the Multidimensional Assessment of Fatigue, and 1 used the Brief Fatigue Index. All 6 studies using the FACIT-Fatigue Scale detected clinically meaningful and statistically significant differences.

Conclusion. VAS, FSS, and FACIT-Fatigue Scale were the most frequently used instruments in adult SLE studies from 2008 to 2017. Many studies detected clinically important changes in fatigue. Fatigue remains a key measure in both clinical trials and observational SLE studies. (First Release June 15 2019; J Rheumatol 2019;46:1470-7; doi:10.3899/jrheum.180831)

Key Indexing Terms:

SYSTEMIC LUPUS ERYTHEMATOSUS

\section{FATIGUE MEASUREMENT}

Systemic lupus erythematosus (SLE) is a chronic multisystem autoimmune disorder with significant morbidity and mortality ${ }^{1}$. Fatigue in SLE is frequent and often debil-

From the Department of Medicine, Division of Rheumatology, McGill University Health Centre, Montreal, Quebec; Division of Rheumatology, Department of Medicine, University of British Columbia Faculty of Medicine, Vancouver, British Columbia; Arthritis Research Centre of Canada, Richmond, British Columbia; Department of Experimental Medicine, University of British Columbia Faculty of Medicine, Vancouver, British Columbia, Canada; Division of Rheumatology, Johns Hopkins University School of Medicine, Baltimore, Maryland; Division of Rheumatology and Clinical Immunology, Department of Medicine, University of Alabama at Birmingham, Birmingham, Alabama, USA.

A. Barbacki, MD, Department of Medicine, Division of Rheumatology, McGill University Health Centre; M. Petri, MD, MPH, Division of Rheumatology, Johns Hopkins University School of Medicine; A. Aviña-Zubieta, $M D, M S c, P h D$, Division of Rheumatology, Department of Medicine, and Department of Experimental Medicine, University of British Columbia Faculty of Medicine, and Arthritis Research Centre of Canada; G.S. Alarcón, MD, MPH, Division of Rheumatology and Clinical Immunology, Department of Medicine, University of Alabama at Birmingham; S. Bernatsky, MD, PhD, Department of Medicine, Division of Rheumatology, McGill University Health Centre.

Address correspondence to Dr. S. Bernatsky, Research Institute of the McGill University Health Centre, 5252 Boulevard de Maisonneuve Ouest, \#3F.51, Montréal, Quebec H4A 3S5, Canada.

E-mail:sasha.bernatsky@mcgill.ca

Accepted for publication January 17, 2019. itating 2,3 ; however, it is a challenging concept to define and measure ${ }^{4,5,6}$. Numerous instruments have been used in past SLE studies, creating difficulties in interpreting and comparing studies. Because it is a subjective symptom that is difficult to define, fatigue is challenging to measure, which may be why so many instruments exist (a 2007 systematic review identified 71 fatigue-specific instruments available for use in research across all patient populations $)^{7}$.

In 2007, the Ad Hoc Committee on SLE Response Criteria for Fatigue conducted a systematic review of fatigue instruments used in SLE studies ${ }^{8}$. They performed a search of articles from 1970 to 2006 and identified 15 instruments. Among these, they recommended the future use of the Krupp Fatigue Severity Scale (FSS) for evaluating fatigue in these patients. It was selected because it was the most frequently used fatigue scale in SLE, had good psychometric properties in patients with SLE, and was validated in multiple languages. In 2011, the Functional Assessment of Chronic Illness Therapy (FACIT)-Fatigue Scale, was also validated in $\operatorname{SLE}^{9,10}$

The aim of our current study was to perform a review of the instruments used to measure fatigue in adult patients with SLE since the 2007 Ad Hoc Committee recommendations

Personal non-commercial use only. The Journal of Rheumatology Copyright ( $)$ 2019. All rights reserved. 
and to summarize fatigue research in patients with SLE over the past 10 years.

\section{MATERIALS AND METHODS}

With the assistance of a librarian, we performed a systematic search of PubMed, Medline, and Embase for all English language publications containing MESH terms "systemic lupus erythematosus/SLE" and "fatigue, asthenia, lassitude" (Supplementary material, available with the online version of this article). Our search was further limited to adults. Both clinical trials and observational studies were included. Case reports, reviews, and animal studies were excluded. Given the previous Ad Hoc Committee review article in $2007^{8}$, we limited our search to articles published between 2008 and October 2017 inclusively. Duplicates were subsequently removed.

Abstracts of the articles obtained with the preliminary search were screened by a single reviewer (AB). After initial screening, full texts were reviewed for inclusion. Publications with a clearly defined adult SLE population, and studying fatigue as a primary or secondary endpoint, were included in our study. Only publications using validated fatigue instruments were retained; studies were excluded if they measured fatigue only through measures of disease activity or quality of life scores (e.g., Medical Outcomes Study Short Form-36). We extracted information from the included studies regarding their design, objectives, and results. In positive studies, we determined whether the results were clinically significant using the minimal clinically important difference (MCID) specific to the instrument used if one was available in the literature.

\section{RESULTS}

Our search protocol yielded 340 articles after duplicates were removed. Of these, 37 articles met our criteria and were included (Figure 1). Among the 37 studies, 8 fatigue instruments were used (Table 1). The visual analog scale (VAS), Krupp Fatigue Severity Scale (FSS), and FACIT-Fatigue scale were the most frequently used measurements (Table 2, Table 3, and Table 4). The FSS was the most frequently used instrument in both randomized controlled trials (RCT) and observational studies. Twelve of the 37 studies failed to demonstrate a statistically significant difference in fatigue levels related to the exposure of interest. Of these, 6 used the FSS, 3 used the VAS, 2 used the Multidimensional Assessment of Fatigue, and 1 used the Brief Fatigue Inventory (BFI). All 6 studies using the FACIT-Fatigue scale detected clinically meaningful and statistically significant differences. Time until end of followup did not appear to influence study results.

$R C T$. Among the articles analyzed, 12 consisted of RCT; 5 of these studied the effect of biologic drug therapies on fatigue in patients with SLE. Abatacept was associated with a clinically significant reduction in fatigue compared to placebo at a 12-month followup, using a VAS ${ }^{11}$. A small RCT of infliximab suggested improvement in fatigue scores but this failed to reach statistical significance in terms of MCID $^{12}$. Finally, there have been 3 studies each assessing

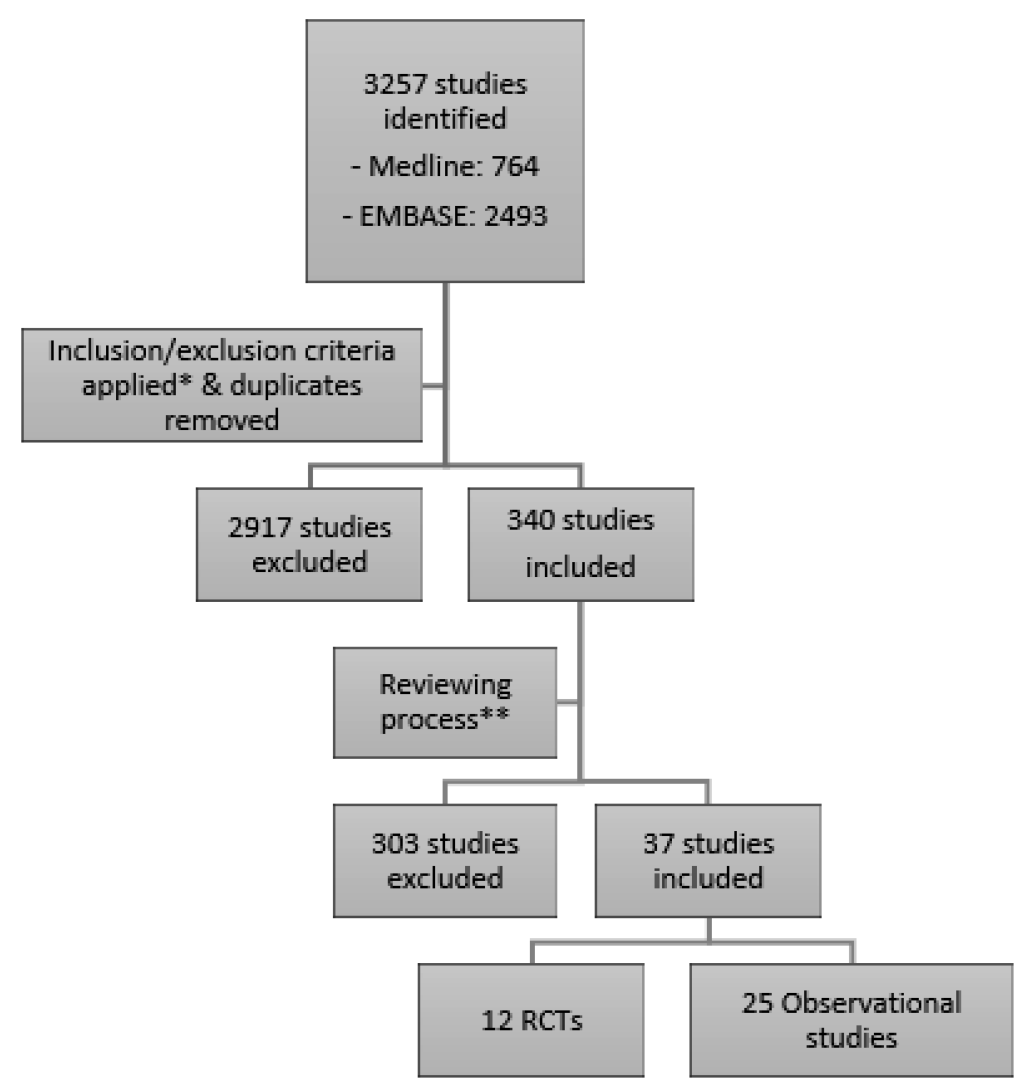

Figure 1. Flowchart of search strategy for selection of included articles. * Case reports, reviews, conference abstracts, and animal studies excluded; search limited to adults and studies in the English language. ** Studies with a clearly defined SLE population, studying fatigue as a primary or secondary endpoint, and using fatigue-specific instruments were included. RCT: randomized controlled trials; SLE: systemic lupus erythematosus. 
Table 1. Fatigue scales used in studies of adults with SLE.

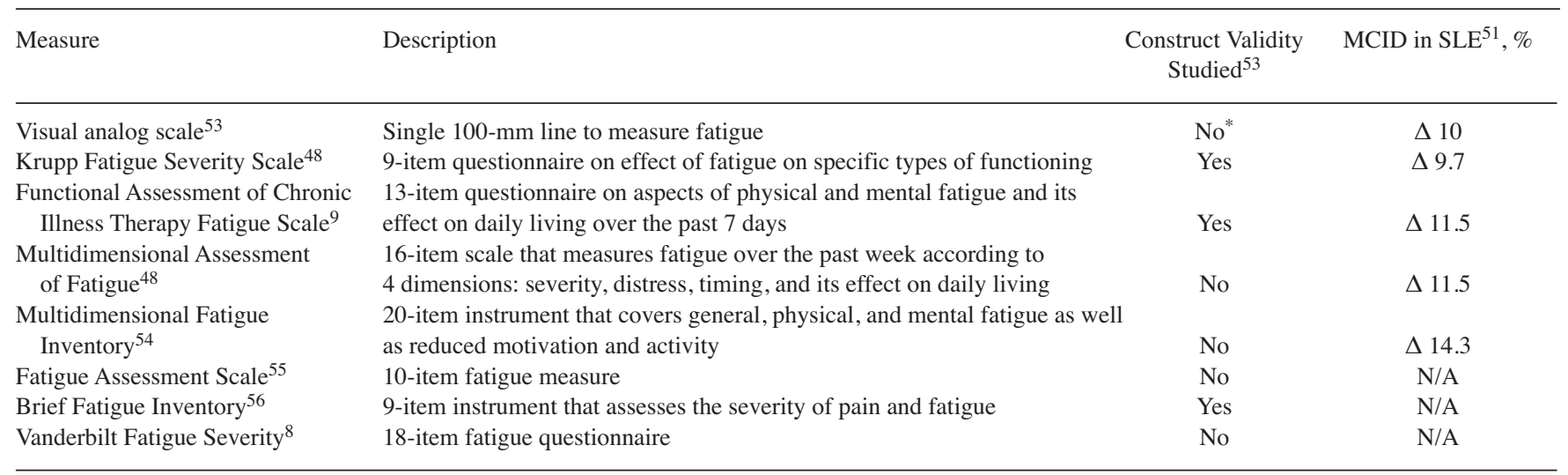

* Validated in other populations, including chronic fatigue syndrome, and stroke. N/A: not available; SLE: systemic lupus erythematosus; MCID: minimal clinically important difference.

Table 2. Frequency of fatigue scales overall and subdivided by study type (clinical trial vs observational).

\begin{tabular}{lccc}
\hline Measures & $\begin{array}{c}\text { SLE Instruments } \\
\text { Used, } \mathrm{n}=38^{1}\end{array}$ & $\begin{array}{c}\text { SLE Instruments in Observational } \\
\text { Studies, } \mathrm{n}=26^{1}\end{array}$ & $\begin{array}{c}\text { SLE Instruments in SLE } \\
\text { Clinical Trials, } \mathrm{n}=12\end{array}$ \\
\hline Visual analog scale & $9(24)$ & $7(27)$ & $2(17)$ \\
Krupp Fatigue Severity Scale & $15(39)$ & $10(38)$ & $5(42)$ \\
Functional Assessment of Chronic Illness Therapy Fatigue scale & $6(16)$ & $2(15)$ & $2(17)$ \\
Multidimensional Assessment of Fatigue & $2(5.3)$ & $2(7.7)$ & - \\
Multidimensional Fatigue Inventory & $3(7.9)$ & - & $1(8)$ \\
Fatigue Assessment Scale & $1(2.6)$ & - & $1(8)$ \\
Brief Fatigue Inventory & $1(2.6)$ & $1(3.8)$ & -
\end{tabular}

Values are $\mathrm{n}(\%) .{ }^{1}$ One study used 2 fatigue measures (37 studies included, but 38 instruments used). SLE: systemic lupus erythematosus.

different B-lymphocyte stimulator (BLyS) antagonists. Belimumab, the first BLyS antagonist on the market, was found to have clinically significant improvements in fatigue at 52 weeks of treatment in a phase III study ${ }^{13}$. Blisibimod was also associated with a significant reduction in fatigue ${ }^{14}$. A study of tabalumab did not show significant improvement in fatigue scores ${ }^{15}$. Interestingly, the first 2 studies, showing positive effects on fatigue, used the FACIT-Fatigue scale, whereas the study of tabalumab used the BFI.

Three RCT addressed nonbiologic drug therapies. One RCT studied the effect of N-acetylcysteine (NAC; thought to be by blocking mTOR in T lymphocytes) on disease activity and fatigue. NAC demonstrated a statistically significant reduction in fatigue, using the FAS. Given that the fatigue levels began to rise again during the third month of treatment, the longterm efficacy of NAC is questionable ${ }^{16}$. An RCT of fish oil did not improve fatigue in SLE ${ }^{17}$. A placebo-controlled trial involving dehydroepiandrosterone (DHEA) similarly failed to demonstrate improvement in fatigue using the Multidimensional Fatigue Inventory ${ }^{18}$.

Acupuncture's benefits on fatigue and pain were studied in a small RCT. There was a trend toward improvement that did not reach statistical significance, possibly due to lack of power ${ }^{19}$. Two RCT of exercise in SLE demonstrated clinically significant reductions in fatigue. Of note, improvement in fatigue (using the FSS) was noted even in patients with low adherence in one of these studies, raising the question of bias in the intervention group ${ }^{20,21}$. Low glycemic index and low-calorie diets were also shown to decrease fatigue in SLE patients when measured by the FSS. Statistical significance was achieved with both diets but only the low glycemic index diet met the $\mathrm{MCID}^{22}$.

Observational studies. Twenty-five observational studies were included. As previously described in the literature, patients with SLE were clinically more fatigued compared to age-matched controls ${ }^{23}$. Regarding predictors, DHEA levels and obesity were not clearly associated with fatigue ${ }^{24,25}$. One study aimed to identify potential biomarkers for fatigue in patients with neuropsychiatric SLE. It identified a clinically significant association between A proliferation-induced ligand (APRIL) in cerebrospinal fluid and fatigue ${ }^{26}$. Five observational studies assessing vitamin $\mathrm{D}$ levels and fatigue in SLE demonstrated somewhat different results. One study suggested a trend in improved fatigue levels when vitamin D 
Table 3. Summary of clinical trials with fatigue as an outcome in SLE.

\begin{tabular}{|c|c|c|c|c|c|c|c|}
\hline Authors & Data Collection & Scale & Intervention & Followup, weeks & $\mathrm{N}$ & Findings & Country \\
\hline Greco, et al ${ }^{19}$ & 2004-2006 & FSS & Acupuncture vs minimal needling & $5-6$ & 24 & No difference detected & USA \\
\hline Avaux, et al ${ }^{21}$ & 2012-2013 & FSS & Exercise vs controls & 12 & 45 & $\begin{array}{l}\text { Clinically significant } \\
\text { improvement* }\end{array}$ & Belgium \\
\hline Davies, et $a l^{22}$ & Published 2012 & FSS & Low GI diet and LC diet vs placebo & 6 & 23 & $\begin{array}{l}\text { Clinically significant } \\
\text { improvement with GI diet*, } \\
\text { ut only statistically significant } \\
\text { improvement with LC diet } \\
\text { (did not meet MCID) }\end{array}$ & UK \\
\hline Bogdanovic, et a ${ }^{20}$ & Published 2015 & FSS & Aerobic and isotonic exercise & 6 & 60 & $\begin{array}{l}\text { Clinically significant } \\
\text { improvement* }\end{array}$ & Serbia \\
\hline Arriens, et $a l^{17}$ & Published 2015 & FSS & Fish oil vs PBO & 26 & 50 & No difference & USA \\
\hline Strand, et al $l^{13}$ & $2007-2010$ & FACIT-Fatigue & Belimumab or PBO & $\begin{array}{l}52(\mathrm{n}=865) \\
76(\mathrm{n}=819)\end{array}$ & 1684 & $\begin{array}{l}\text { Clinically significant } \\
\text { improvement* }\end{array}$ & Multicenter \\
\hline Petri, et al ${ }^{14}$ & 2010-2012 & FACIT-Fatigue & Blisibimod or PBO & 24 & 547 & $\begin{array}{l}\text { Clinically significant } \\
\text { improvement* }\end{array}$ & $\begin{array}{l}\text { USA and } \\
\text { Brazil }\end{array}$ \\
\hline Hartkamp, et al ${ }^{18}$ & Published 2010 & MFI & DHEA vs PBO & 52 & 60 & No difference detected & the Netherlands \\
\hline Lai, et l $^{16}$ & 2009-2011 & FAS & $\begin{array}{l}\text { PBO vs escalating doses of } \\
\mathrm{N} \text {-acetylcysteine }\end{array}$ & 12 & 36 & $\begin{array}{l}\text { Statistically significant } \\
\text { improvement }\end{array}$ & USA \\
\hline Merrill, et al ${ }^{15}$ & 2011-2014 & BFI & Tabalumab vs PBO & 52 & 1124 & No difference detected & Multicenter \\
\hline
\end{tabular}

* Met MCID (therefore both statistically and clinically significant difference detected). MCID: minimal clinically important difference; FSS: Krupp Fatigue Severity Scale; GI: glycemic index; LC: low-calorie; FACIT-F: Functional Assessment of Chronic Illness Therapy-Fatigue Scale; PBO: placebo; VAS: visual analog scale; MFI: Multidimensional Fatigue Inventory; DHEA: dehydroepiandrosterone; BFI: Brief Fatigue Inventory; FAS: Fatigue Assessment Scale; SLE: systemic lupus erythematosus.

deficiency/insufficiency was corrected with supplementation, but this did not reach statistical significance ${ }^{27}$. Of the 4 remaining vitamin D studies, 2 demonstrated clinically significant (i.e., met MCID) increased fatigue with low vitamin $\mathrm{D}$ levels ${ }^{28,29}$ while the other 2 were unable to demonstrate associations ${ }^{30,31}$. Two studies aimed to determine the relationship between muscle strength and fatigue in SLE. One study demonstrated decreased strength with increased fatigue $^{32}$, while the other was unable to establish this relationship ${ }^{33}$. Three studies demonstrated a clinically significant association between work disability and fatigue in patients with $\mathrm{SLE}^{34,35,36}$. Finally, lower physical activity, sleep disturbances, pain, anxiety, and depression were all found to be associated with fatigue levels in SLE ${ }^{37-45}$. Regarding interventions, belimumab was shown to clinically significantly decrease fatigue in patients with SLE in an observational study ${ }^{46}$. A study of a fatigue and activity management education intervention, administered by occupational therapists, was unable to demonstrate decreased fatigue in $\mathrm{SLE}^{47}$.

Among observational studies, most studies with large sample sizes $(>100)$ demonstrated a clinically significant change in fatigue $29,35,36,37,39-43,45$. Smaller studies were unable to demonstrate changes, suggesting that they were underpowered $26,28,31,34,48$.

\section{DISCUSSION}

This review is an important update of instruments used to measure fatigue in SLE in the past 10 years. In this systematic review the VAS, FSS, and FACIT-Fatigue scale were the most frequently used instruments to measure fatigue in adult SLE studies from 2008 to 2017. The VAS is a simple analog scale in which patients mark with an " $x$ " their level of fatigue on a 100-mm line. The advantages are its ease of use and quick administration. Unfortunately, although validated in other populations, this instrument has not yet been studied in SLE and does not consider fatigue's effect on daily living. Additionally, many studies fail to provide the anchors used with the scale, rendering it difficult to compare their results.

Krupp's FSS was the most frequently used instrument in our study and was the instrument recommended for use by the 2007 Ad Hoc Committee ${ }^{8}$. It was designed to measure the effect of fatigue on functional outcomes such as exercise, motivation, and daily activities. It has been validated for use in $\mathrm{SLE}^{48}$.

The FACIT-Fatigue scale is a 13-item questionnaire (originally developed in cancer patients) that measures aspects of physical and mental fatigue and their effects on daily living and functioning. The FACIT-Fatigue scale had not yet been validated in SLE when the Ad Hoc Committee made its recommendations in 2007. The first validation

$$
\text { Personal non-commercial use only. The Journal of Rheumatology Copyright (c) 2019. All rights reserved. }
$$


Table 4. Summary of observational studies reporting fatigue as an outcome in SLE.

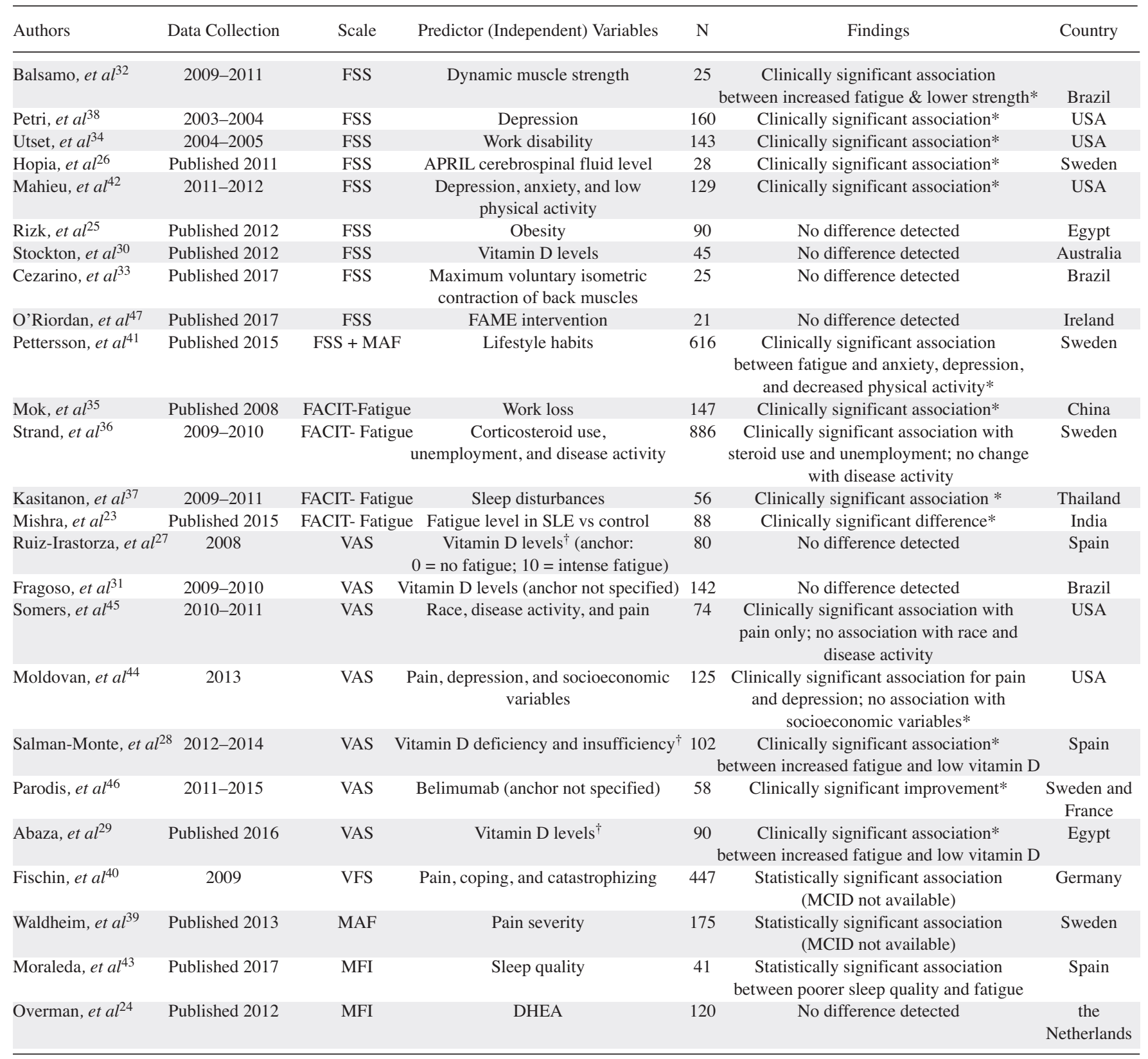

* Met MCID (therefore both statistically and clinically significant difference detected). ${ }^{\dagger}$ Anchor: $0=$ no fatigue; $10=$ intense fatigue. APRIL: A proliferation-induced ligand; MCID: minimal clinically important difference; DHEA: dehydroepiandrosterone; FSS: Krupp Fatigue Severity Scale; FAME: Fatigue and Activity Management Education; FACIT-Fatigue: Functional Assessment of Chronic Illness Therapy-Fatigue Scale; VAS: visual analog scale; MFI: Multidimensional Fatigue Inventory; SLE: systemic lupus erythematosus; MAF: Multidimensional Assessment of Fatigue.

study of FACIT-Fatigue scale in SLE was published in $2011^{10}$. Like FSS, the FACIT-Fatigue scale has been shown to have good psychometric properties and is easy and quick to administer $(<5 \mathrm{~min})$. Interestingly, all studies that used the FACIT-Fatigue scale found clinically significant associations ${ }^{13,14,23,35,36,37}$.

The US Food and Drug Administration (FDA) strongly encourages the use of patient-reported outcomes (PRO) as secondary endpoints in SLE clinical trials. Both the FDA and European Medicine Agency emphasize fatigue as being one of the most important PRO to consider. Though no specific scale is recommended, they state that the instrument used should be well defined and have been validated in SLE trial populations ${ }^{49}$. Difficulty in showing effects of an intervention on fatigue in SLE may well be due to study power for many of the studies that we reviewed. 
The FACIT-Fatigue scale and FSS have good construct validity ${ }^{9,50}$. Both scales have an MCID calculated for patients with SLE $^{51}$, which allows them to demonstrate changes in fatigue that are both statistically and clinically (in terms of MCID) significant. FACIT-Fatigue scale has been reported to have superior internal consistency and greater sensitivity to change than FSS ${ }^{51}$. FACIT-Fatigue scale may be more sensitive to detect subjectively important changes in fatigue levels and potentially able to detect a change in smaller sample sizes ${ }^{51}$. Using focus groups, the FACIT-Fatigue scale has been shown to have good content validity, which means that it appears to be relevant and sufficient for properly assessing fatigue in patients with SLE 5 ,9. The content validity for FSS has not yet been studied ${ }^{52}$. Fatigue remains an important issue in patients with SLE. Our literature review revealed a small number of clinical trial studies with important reductions in fatigue with medications and nonpharmacologic approaches. Many of these studies used either the FSS, which was recommended for use by the 2007 Ad Hoc Committee, or the FACIT-Fatigue scale, which has demonstrated both superior internal consistency and greater sensitivity compared to FSS ${ }^{51}$. The VAS, though easy to use and often used in longterm observational studies, has not been validated in SLE and does not record fatigue's functional effect on patients.

As in any review, our results have potential limitations, and these are partially driven by limitations in the literature. We found that observational studies with larger sample sizes more consistently demonstrated a statistically significant change in fatigue $^{24,29,35,36,37,39-43,45}$. This suggests that some of the smaller studies included were underpowered $26,28,31,34,48$. Regarding RCT results, most had a followup time of $<52$ weeks, and hence limited our ability to comment on longterm effects.

The VAS, FSS, and FACIT-Fatigue scale were the most frequently used instruments in adult SLE studies from 2008 to 2017. Many studies detected clinically important changes in fatigue. Fatigue remains a key measure in both clinical trials and observational SLE studies. Just as RCT now generally require fatigue scores, fatigue (for example, measured with the FSS or FACIT-Fatigue scale) should be a part of the core data collection for observational SLE studies.

\section{ONLINE SUPPLEMENT}

Supplementary material accompanies the online version of this article.

\section{REFERENCES}

1. Yurkovich M, Vostretsova K, Chen W, Aviña-Zubieta JA. Overall and cause-specific mortality in patients with systemic lupus erythematosus: a meta-analysis of observational studies. Arthritis Care Res 2014;66:608-16.

2. del Pino-Sedeño T, Trujillo-Martin MM, Ruiz-Irastorza G, Cuellar-Pompa L, de Pascual-Medina AM, Serrano-Aguilar P, et al; Spanish Systemic Lupus Erythematosus CPG Development Group. Effectiveness of nonpharmacologic interventions for decreasing fatigue in adults with systemic lupus erythematosus: a systematic review. Arthritis Care Res 2016;68:141-8.

3. Ahn GE, Ramsey-Goldman R. Fatigue in systemic lupus erythematosus. Int J Clin Rheumtol 2012;7:217-27.

4. Mattsson M, Moller B, Stamm T, Gard G, Bostrom C. Uncertainty and opportunities in patients with established systemic lupus erythematosus: a qualitative study. Musculoskeletal Care 2012; 10:1-12.

5. Ramsey-Goldman R, Rothrock N. Fatigue in systemic lupus erythematosus and rheumatoid arthritis. PM R 2010;2:384-92.

6. Cleanthous S, Tyagi M, Isenberg DA, Newman SP. What do we know about self-reported fatigue in systemic lupus erythematosus? Lupus 2012;21:465-76.

7. Hjollund $\mathrm{NH}$, Andersen $\mathrm{JH}$, Bech P. Assessment of fatigue in chronic disease: a bibliographic study of fatigue measurement scales. Health Qual Life Outcomes 2007;5:12.

8. Ad Hoc Committee on Systemic Lupus Erythematosus Response Criteria for Fatigue. Measurement of fatigue in systemic lupus erythematosus: a systematic review. Arthritis Rheum 2007;57:1348-57.

9. Kosinski M, Gajria K, Fernandes AW, Cella D. Qualitative validation of the FACIT-fatigue scale in systemic lupus erythematosus. Lupus 2013;22:422-30.

10. Lai JS, Beaumont JL, Ogale S, Brunetta P, Cella D. Validation of the functional assessment of chronic illness therapy-fatigue scale in patients with moderately to severely active systemic lupus erythematosus, participating in a clinical trial. J Rheumatol 2011;38:672-9.

11. Merrill JT, Burgos-Vargas R, Westhovens R, Chalmers A, D'Cruz $\mathrm{D}$, Wallace DJ, et al. The efficacy and safety of abatacept in patients with non-life-threatening manifestations of systemic lupus erythematosus: results of a twelve-month, multicenter, exploratory, phase IIb, randomized, double-blind, placebo-controlled trial. Arthritis Rheum 2010;62:3077-87.

12. Uppal SS, Hayat SJ, Raghupathy R. Efficacy and safety of infliximab in active SLE: a pilot study. Lupus 2009;18:690-7.

13. Strand V, Levy RA, Cervera R, Petri MA, Birch H, Freimuth WW, et al; BLISS-52 and -76 Study Groups. Improvements in health-related quality of life with belimumab, a B-lymphocyte stimulator-specific inhibitor, in patients with autoantibody-positive systemic lupus erythematosus from the randomised controlled BLISS trials. Ann Rheum Dis 2014;73:838-44.

14. Petri MA, Martin RS, Scheinberg MA, Furie RA. Assessments of fatigue and disease activity in patients with systemic lupus erythematosus enrolled in the phase 2 clinical trial with blisibimod. Lupus 2017;26:27-37.

15. Merrill JT, van Vollenhoven RF, Buyon JP, Furie RA, Stohl W, Morgan-Cox M, et al. Efficacy and safety of subcutaneous tabalumab, a monoclonal antibody to B-cell activating factor, in patients with systemic lupus erythematosus: results from ILLUMINATE-2, a 52-week, phase III, multicentre, randomised, double-blind, placebo-controlled study. Ann Rheum Dis 2016;75:332-40.

16. Lai ZW, Hanczko R, Bonilla E, Caza TN, Clair B, Bartos A, et al. $\mathrm{N}$-acetylcysteine reduces disease activity by blocking mammalian target of rapamycin in $\mathrm{T}$ cells from systemic lupus erythematosus patients: a randomized, double-blind, placebo-controlled trial. Arthritis Rheum 2012;64:2937-46.

17. Arriens C, Hynan LS, Lerman RH, Karp DR, Mohan C. Placebo-controlled randomized clinical trial of fish oil's impact on fatigue, quality of life, and disease activity in systemic lupus erythematosus. Nutr J 2015;14:82.

18. Hartkamp A, Geenen R, Godaert GL, Bijl M, Bijlsma JW, Derksen $\mathrm{RH}$. Effects of dehydroepiandrosterone on fatigue and well-being in women with quiescent systemic lupus erythematosus: a randomised controlled trial. Ann Rheum Dis 2010;69:1144-7.

19. Greco CM, Kao AH, Maksimowicz-McKinnon K, Glick RM, Houze

Personal non-commercial use only. The Journal of Rheumatology Copyright @ 2019 . All rights reserved. 
M, Sereika SM, et al. Acupuncture for systemic lupus erythematosus: a pilot RCT feasibility and safety study. Lupus 2008; 17:1108-16.

20. Bogdanovic G, Stojanovich L, Djokovic A, Stanisavljevic N. Physical activity program is helpful for improving quality of life in patients with systemic lupus erythematosus. Tohoku J Exp Med 2015;237:193-9.

21. Avaux M, Hoellinger P, Nieuwland-Husson S, Fraselle V, Depresseux G, Houssiau FA. Effects of two different exercise programs on chronic fatigue in lupus patients. Acta Clin Belg 2016;71:403-6.

22. Davies RJ, Lomer MC, Yeo SI, Avloniti K, Sangle SR, D'Cruz DP. Weight loss and improvements in fatigue in systemic lupus erythematosus: a controlled trial of a low glycaemic index diet versus a calorie restricted diet in patients treated with corticosteroids. Lupus 2012;21:649-55.

23. Mishra R, Dhir V, Aggarwal A. The relationship of fatigue with quality of life in patients with systemic lupus erythematosus having low disease activity. Indian J Rheumatol 2015;10:125-8.

24. Overman CL, Hartkamp A, Bossema ER, Bijl M, Godaert GL, Bijlsma JW, et al. Fatigue in patients with systemic lupus erythematosus: the role of dehydroepiandrosterone sulphate. Lupus 2012;21:1515-21.

25. Rizk A, Gheita TA, Nassef S, Abdallah A. The impact of obesity in systemic lupus erythematosus on disease parameters, quality of life, functional capacity and the risk of atherosclerosis. Int J Rheum Dis 2012;15:261-7.

26. Hopia L, Thangarajh M, Khademi M, Laveskog A, Wallstrom E, Svenungsson E, et al. Cerebrospinal fluid levels of a proliferation-inducing ligand (APRIL) are increased in patients with neuropsychiatric systemic lupus erythematosus. Scand J Rheumatol 2011;40:363-72.

27. Ruiz-Irastorza G, Gordo S, Olivares N, Egurbide MV, Aguirre C Changes in vitamin D levels in patients with systemic lupus erythematosus: effects on fatigue, disease activity, and damage. Arthritis Care Res 2010;62:1160-5.

28. Salman-Monte TC, Torrente-Segarra V, Almirall M, Corzo P, Mojal S, Carbonell-Abello J. Prevalence and predictors of vitamin D insufficiency in supplemented and non-supplemented women with systemic lupus erythematosus in the Mediterranean region. Rheumatol Int 2016;36:975-85.

29. Abaza NM, El-Mallah RM, Shaaban A, Mobasher SA, Al-Hassanein $\mathrm{KF}$, Abdel Zaher AA, et al. Vitamin D deficiency in Egyptian systemic lupus erythematosus patients: how prevalent and does it impact disease activity? Integr Med Insights 2016;11:27-33.

30. Stockton KA, Kandiah DA, Paratz JD, Bennell KL. Fatigue, muscle strength and vitamin D status in women with systemic lupus erythematosus compared with healthy controls. Lupus 2012; 21:271-8

31. Fragoso TS, Dantas AT, Marques CD, Rocha Junior LF, Melo JH, Costa AJ, et al. 25-Hydroxyivitamin D3 levels in patients with systemic lupus erythematosus and its association with clinical parameters and laboratory tests. Rev Bras Reumatol 2012;52:60-5.

32. Balsamo S, da Mota LM, de Carvalho JF, Nascimento Dda C, Tibana RA, de Santana FS, et al. Low dynamic muscle strength and its associations with fatigue, functional performance, and quality of life in premenopausal patients with systemic lupus erythematosus and low disease activity: a case-control study. BMC Musculoskelet Disord 2013;14:263.

33. Cezarino RS, Cardoso JR, Rodrigues KN, Magalhaes YS, Souza TY, Mota L, et al. Chronic low back pain in patients with systemic lupus erythematosus: prevalence and predictors of back muscle strength and its correlation with disability. Rev Bras Reumatol Engl Ed 2017;57:438-44

34. Utset TO, Chohan S, Booth SA, Laughlin JC, Kocherginsky M,
Schmitz A. Correlates of formal work disability in an urban university systemic lupus erythematosus practice. J Rheumatol 2008;35:1046-52.

35. Mok CC, Cheung MY, Ho LY, Yu KL, To CH. Risk and predictors of work disability in Chinese patients with systemic lupus erythematosus. Lupus 2008;17:1103-7.

36. Strand V, Galateanu C, Pushparajah DS, Nikai E, Sayers J, Wood R, et al. Limitations of current treatments for systemic lupus erythematosus: a patient and physician survey. Lupus 2013; 22:819-26.

37. Kasitanon N, Achsavalertsak U, Maneeton B, Wangkaew S, Puntana $\mathrm{S}$, Sukitawut $\mathrm{W}$, et al. Associated factors and psychotherapy on sleep disturbances in systemic lupus erythematosus. Lupus 2013;22:1353-60.

38. Petri M, Naqibuddin M, Carson KA, Wallace DJ, Weisman MH, Holliday SL, et al. Depression and cognitive impairment in newly diagnosed systemic lupus erythematosus. J Rheumatol 2010;37:2032-8

39. Waldheim E, Elkan AC, Pettersson S, van Vollenhoven R, Bergman $\mathrm{S}$, Frostegard J, et al. Health-related quality of life, fatigue and mood in patients with SLE and high levels of pain compared to controls and patients with low levels of pain. Lupus 2013; 22:1118-27.

40. Fischin J, Chehab G, Richter JG, Fischer-Betz R, Winkler-Rohlfing $\mathrm{B}$, Willers R, et al. Factors associated with pain coping and catastrophising in patients with systemic lupus erythematosus: a cross-sectional study of the LuLa-cohort. Lupus Sci Med 2015;2:e00113.

41. Pettersson S, Bostrom C, Eriksson K, Svenungsson E, Gunnarsson I, Henriksson EW. Lifestyle habits and fatigue among people with systemic lupus erythematosus and matched population controls. Lupus 2015;24:955-65.

42. Mahieu MA, Ahn GE, Chmiel JS, Dunlop DD, Helenowski IB, Semanik P, et al. Fatigue, patient reported outcomes, and objective measurement of physical activity in systemic lupus erythematosus. Lupus 2016;25:1190-9.

43. Moraleda V, Prados G, Martinez MP, Sanchez AI, Sabio JM, Miro E. Sleep quality, clinical and psychological manifestations in women with systemic lupus erythematosus. Int J Rheum Dis 2017;20:1541-50.

44. Moldovan I, Cooray D, Carr F, Katsaros E, Torralba K, Shinada S, et al. Pain and depression predict self-reported fatigue/energy in lupus. Lupus 2013;22:684-9.

45. Somers TJ, Kurakula PC, Criscione-Schreiber L, Keefe FJ, Clowse ME. Self-efficacy and pain catastrophizing in systemic lupus erythematosus: relationship to pain, stiffness, fatigue, and psychological distress. Arthritis Care Res 2012;64:1334-40.

46. Parodis I, Sjowall C, Jonsen A, Ramskold D, Zickert A, Frodlund $\mathrm{M}$, et al. Smoking and pre-existing organ damage reduce the efficacy of belimumab in systemic lupus erythematosus. Autoimmun Rev 2017;16:343-51

47. O'Riordan R, Doran M, Connolly D. Fatigue and activity management education for individuals with systemic lupus erythematosus. Occup Ther Int 2017:4530104.

48. Neuberger GB. Measures of fatigue: The Fatigue Questionnaire, Fatigue Severity Scale, Multidimensional Assessment of Fatigue Scale, and Short Form-36 Vitality (Energy/Fatigue) Subscale of the Short Form Health Survey. Arthritis Care Res 2003;S5: S175-83.

49. US Department of Health and Human Services, Food and Drug Administration. Guidance for industry. Systemic lupus erythematosus - developing drugs for treatment. [Internet. Accessed May 13, 2019.] Available from: www.fda.gov/downloads/ Drugs/GuidanceComplianceRegulatoryInformation/Guidances/ ucm072063.pdf

50. Krupp LB, LaRocca NG, Muir-Nash J, Steinberg AD. The fatigue

Personal non-commercial use only. The Journal of Rheumatology Copyright $\odot$ (2019. All rights reserved 
severity scale. Application to patients with multiple sclerosis and systemic lupus erythematosus. Arch Neurol 1989;46:1121-3.

51. Goligher EC, Pouchot J, Brant R, Kherani RB, Avina-Zubieta JA, Lacaille D, et al. Minimal clinically important difference for 7 measures of fatigue in patients with systemic lupus erythematosus. J Rheumatol 2008;35:635-42.

52. Holloway L, Humphrey L, Heron L, Pilling C, Kitchen H, Hojbjerre $\mathrm{L}$, et al. Patient-reported outcome measures for systemic lupus erythematosus clinical trials: a review of content validity, face validity and psychometric performance. Health Qual Life Outcomes 2014;12:116.

53. Tseng BY, Gajewski BJ, Kluding PM. Reliability, responsiveness, and validity of the visual analog fatigue scale to measure exertion fatigue in people with chronic stroke: a preliminary study. Stroke Res Treat 2010;2010:412964.

54. Gentile S, Delarozière J, Favre F, Sambuc R, San Marco JL. Validation of the French 'multidimensional fatigue inventory'(MFI 20). Eur J Cancer Care 2003;12:58-64.

55. Michielsen HJ, De Vries J, Van Heck GL. Psychometric qualities of a brief self-rated fatigue measure: The Fatigue Assessment Scale. J Psychosom Res 2003;54:345-52.

56. Shahid A, Wilkinson K, Marcu S, Shapiro CM. Brief Fatigue Inventory. In: STOP, THAT and one hundred other sleep scales. New York: Springer-Verlag; 2011:75-7. 